\title{
Assessment of the Podiatric Risk on Diabetics in Dakar Hospital Area: Cross-Sectional Study in Regard to 142 Patients
}

\author{
Abdoulaye Leye, Ngone Diaba Diack, Yakham Mohamed Leye, Nafy Ndiaye, Alex Bahati, \\ Ameth Dieng, Daouda Thioub, Maïmouna Senghor, Maouly Fall, Samira Elfajri
}

Internal Medicine/Endocrinology-Diabetology Department, Teaching Hospital of Pikine, Dakar, Senegal

Email: ablayleye@hotmail.com

How to cite this paper: Leye, A., Diack, N.D., Leye, Y.M., Ndiaye, N., Bahati, A., Dieng, A., Thioub, D., Senghor, M., Fall, M. and Elfajri, S. (2018) Assessment of the Podiatric Risk on Diabetics in Dakar Hospital Area: Cross-Sectional Study in Regard to 142 Patients. Journal of Diabetes Mellitus, 8, 1-8.

https://doi.org/10.4236/jdm.2018.81001

Received: December 25, 2017

Accepted: January 13, 2018

Published: January 16, 2018

Copyright $\odot 2018$ by authors and Scientific Research Publishing Inc. This work is licensed under the Creative Commons Attribution International License (CC BY 4.0).

http://creativecommons.org/licenses/by/4.0/

c) (i) Open Access

\begin{abstract}
The prevention of diabetic foot goes through a systematic podiatric assessment of diabetic patients permitting to identify the foot at risk. Then, we realized a study in the Internal Medicine Department at Pikine Teaching Hospital in Dakar with the assessment of foot risk on admitted diabetic patients as our main objective. Methods: It was about a prospective cross-sectional, descriptive and analytic study done on 18 months period. Results: Overall, 142 patients were gathered. The average age was 56.22 years and the sex-ratio was 0.67. $87.2 \%$ of the patients were running type 2 diabetes. The capillary blood glucose and glycated hemoglobin were respectively around $3.24 \mathrm{~g} / \mathrm{L}$ and $9 \%$. High Blood Pressure was found in $62 \%$ of cases. The type of footwear most used by our patients was sandals (96.3\%). Also, 30.6\% of patients walked barefoot. Prior ulceration and/or amputation were noted in $30 \%$ of cases. During the foot examination, a lesion was found in $15.5 \%$ of patients. Loss of monofilament sensitivity was about $66.7 \%$. The Ankle-Brachial Index (ABI) less than 0.9 was recorded in $34 \%$ of patients and at least a quarter of patients were posteriorly tibial pulselessness. The gradation of the foot risk according to the International Working Group of the Diabetic Foot (IWGDF) was established as follow: grade $0(58 \%)$, grade $1(9.8 \%)$, grade $2(14.3 \%)$, grade 3 (17.3\%). The presence of neuropathy (OR 12. 162 [3.368 - 43.923]; $\mathrm{p}=0.000$ ), plantar keratosis (OR 2.87 [1.119 - 7.399]; $\mathrm{p}=0.024$ ) and the absence of pulse perception (OR 9.00 [3.205 - 25.414]; $\mathrm{p}=0.000$ ) were significant associated factors of foot injury occurrence on our patients. Conclusion: The prevention of diabetic foot in emerging countries is accessible by a systematic clinical examination of all diabetic feet and the awareness of adapted footwear.
\end{abstract}

\section{Keywords}

Foot Risk, Diabetes, Dakar 


\section{Introduction}

Foot injuries on diabetics are the first non-traumatic cause of lower limbs amputation [1]. In Africa, the socio-economical precariousness and the diagnostic delay of the diabetes are both risk factors of diabetic foot occurrence [1]. In Senegal, this complication represents $2.8 \%$ of the complaints in diabetology [2].

Diabetic foot is a public health issue by its prevalence but also the cost of the management and the functional disability it causes. Therefore, it's necessary to prevent its occurrence by a systematic foot examination. This examination allows an assessment of the foot risk and the screening of early lesions [3].

In this perspective, we initiated this prospective study in Dakar hospital area. It was about evaluating the podiatric risk on admitted diabetic patients at the Internal Medicine/Diabetology Department in Pikine Teaching Hospital of Dakar. This study should also allow to identify the associated factors of foot lesion occurrence in this population.

\section{Methodology}

It was about a cross-sectional, prospective, descriptive and analytical study that happened in a 18-months (period from January 1st to June 30th 2014). It concerned diabetic individuals hospitalized in the Internal Medicine Unit of CNHP during the study. Patients were recruited after their oral consent. Patients who didn't accept or who couldn't be examined were not included. Data regarding their status, diabetic field, podiatric risk factors and foot examination results were noted in a record card. After these data, a foot risk gradation was set according to the International Consensus on Diabetic Foot approved by the International Working Group on the Diabetic foot [4].

Data were analyzed afterwards by a software SPSS version 20.0. The proportion was considered as significant for a value less than 0.05 .

\section{Results}

\subsection{Epidemiological Data}

Overall 142 files were collected during the study. The average age of the patients was 56.22 years old with extremes of 16 and 85 years. Sex ratio male/female was 0.67 .

\subsection{Data Regarding Diabetic Field}

Type 2 diabetes represented $87 \%$ of the cases against $11 \%$ of type 1 diabetes. Recent discovery of the diabetic status occurred in 30 patients. It has been known and treated for more than 10 years in around half of the included individual (49\%). Among the patients already known diabetics, before their admission ( $\mathrm{n}=$ 112 ), $38.4 \%$ were under insulin and $67 \%$ with non-insulinic treatment, particularly with Metformin (42\%). Capillary blood glucose while admission was at average $3.24 \mathrm{~g} / \mathrm{L}$. Glycated hemoglobin (HbA1C) was over than $7 \%$ in more than three quarters of cases $(76.5 \%)$ when checked. The average in our study was $9 \%$ 
[extremes 5\% - 14\%].

Others cardiovascular associated risk factors were noted such as hypertension mainly in $62 \%$ of patients, smoking (15.5\%), overweight (23\%) and obesity $(18 \%)$.

\subsection{Podiatric Risk Factors}

The most used footwear type by our patients was sandals (96.3\%). Patients who walked barefoot represented $30.6 \%$ in our series (Figure 1). Patients with closed shoe were $28.9 \%$ of the cases. Diabetic individuals in our series didn't wear shoes in $62.1 \%$ of the cases. Prior ulcerations and amputations were respectively found in 34 patients $(24 \%)$ and $5.9 \%$ of cases. Gait disorders were noted on 19 patients around $13.4 \%$. Traumatic pedicure cares were realized on around $20 \%$ of our patients.

\subsection{Local Foot Examination Results}

The main noted abnormalities during foot examination in our patients are highlighted in Figure 2. Cutaneous trophic disorders were essentially as skin depilated, cardboard, waxy and/or fine. A foot lesion was recorded in 22 patients (15.5\%) with 12 men and 10 women. The average age was 58.59 years and they were type 2 diabetics in $95.5 \%$ of the cases. The hallmarks of the found lesions are set in Table 1. Lesions were like ulcerations, often associated with necrosis (Figure 3), gangrene (Figure 4) and abscess.

Monofilament sensitivity was missing in $66.7 \%$ of our patients and uninterpretable in $19 \%$ of patients. In 22 patients having a foot lesion, the sensibility was missing in 14 and uninterpretable in 4 of them.

The Ankle-Brachial Index (ABI) was low (less than 0.9) in 48 patients. Pulseless regarded particularly posterior tibial pulse that was perceived in $26.1 \%$ of the cases.

The foot risk gradation in our patients according to the IWGDF is set in Figure 5. Patients with feet at podiatric risk represented $58.7 \%$ in our series.

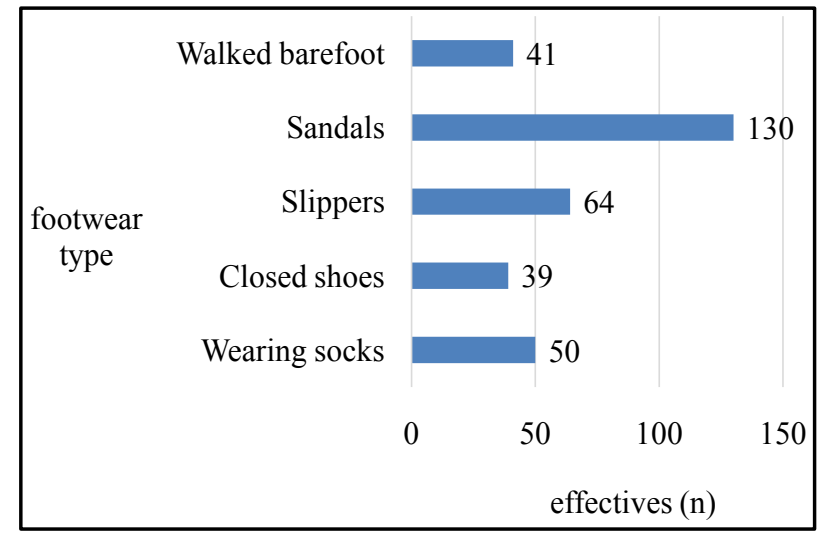

Figure 1. Footwear type used in our series. $\mathrm{N}=$ number of patient often using this footwear type. 


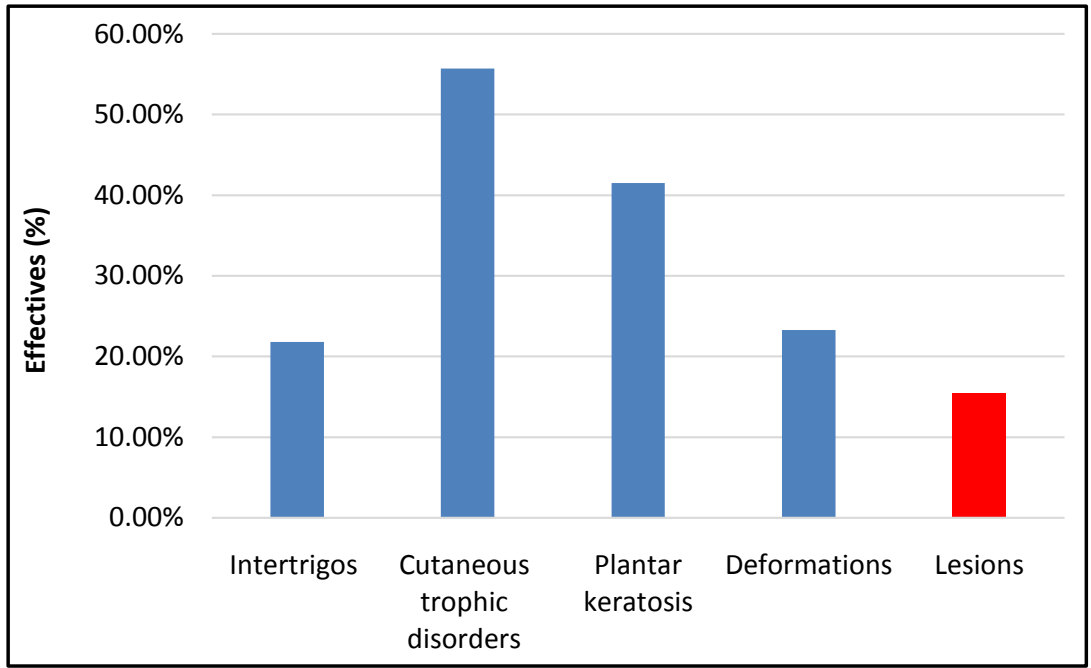

Figure 2. Main abnormalities found during local foot examination on our patients. \%: percentage of patients with corresponding abnormality.

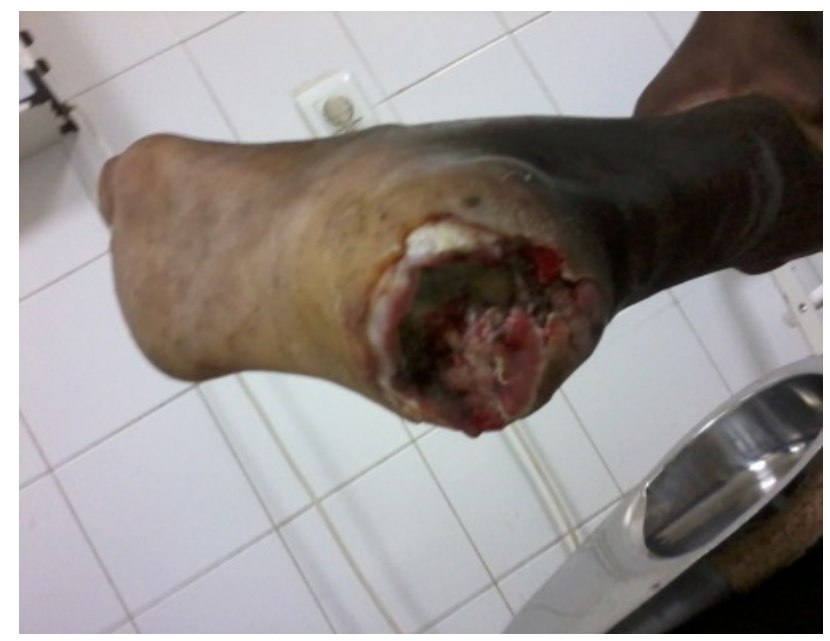

Figure 3. Deep ulceration on the heel with necrotic areas.

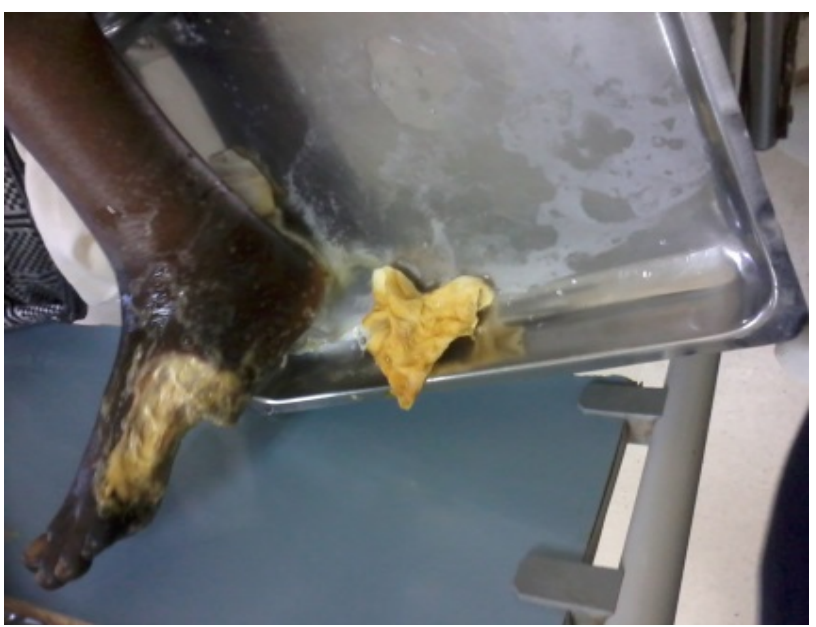

Figure 4. Mixed foot gangrene in particular vascular and infectious. 


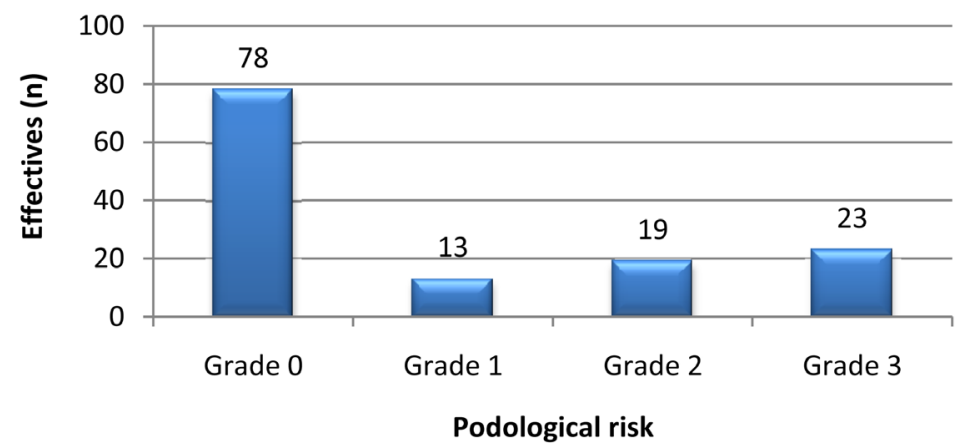

Figure 5. Repartition of our patients according the foot risk gradation (IWGDF). $\mathrm{n}=$ number of patients.

Table 1. Hallmarks of diabetic foot in our series.

\begin{tabular}{|c|c|c|c|}
\hline \multicolumn{3}{|c|}{ WORKFORCE } & \multirow{2}{*}{$\begin{array}{c}\text { PERCENTAGE } \\
63.6\end{array}$} \\
\hline \multirow{3}{*}{ Type of lesion } & Ulceration & 14 & \\
\hline & Gangrene & 9 & 40.9 \\
\hline & Abscess & 3 & 13.6 \\
\hline \multirow{2}{*}{ Number of lesions } & Unique & 18 & 81.8 \\
\hline & Multiple & 4 & 18.2 \\
\hline \multirow{6}{*}{ Lesion localisation } & Toes & 5 & 22.7 \\
\hline & Sole & 9 & 40.9 \\
\hline & Back of the foot & 3 & 13.6 \\
\hline & Malleolus & 6 & 27.2 \\
\hline & Heel & 2 & 9.1 \\
\hline & Leg & 1 & 4.5 \\
\hline \multirow{3}{*}{ Evolutionary stages lesions } & Yellow & 19 & 86.4 \\
\hline & Black & 8 & 36.4 \\
\hline & Red & 4 & 18.2 \\
\hline \multirow{2}{*}{ Bone and articulation visibilty } & Yes & 2 & 9.1 \\
\hline & No & 20 & 90.9 \\
\hline \multirow{3}{*}{ Lesion aspect } & Fibrinous & 10 & 45.5 \\
\hline & Wet & 8 & 36.4 \\
\hline & Dry & 9 & 40.9 \\
\hline \multirow{3}{*}{ Borders } & Unstuck & 2 & 9.1 \\
\hline & shredded & 8 & 36.4 \\
\hline & Well limited & 12 & 54.5 \\
\hline \multirow{2}{*}{ Communicating injuries } & Yes & 3 & 13.6 \\
\hline & No & 19 & 86.4 \\
\hline \multirow{7}{*}{ Local inflammatory signs } & Purulent discharge & 6 & 27.3 \\
\hline & Deep wound & 3 & 13.6 \\
\hline & Edema & 15 & 68.2 \\
\hline & Nasty smelt & 10 & 45.5 \\
\hline & Local heat & 12 & 54.5 \\
\hline & Redness & 5 & 22.7 \\
\hline & Bone contact & 2 & 9.1 \\
\hline
\end{tabular}




\subsection{Analytical Study}

The main factors significantly associated with the presence of a foot lesion in our series are listed in Table 2. Among them, only the wear of closed shoe had a protective effect on lesion occurrence. The existence of neuropathy was an important factor associated to the occurrence of diabetic foot in our patients.

This neuropathy was significantly and positively correlated at an age over than 55 years (OR: 2.773 [IC 95\%: $1.121-6.856$ ]; $\mathrm{p}=0.024$ ), a diabetes evolving since more than 5 years (OR: 5.230 [IC 95\%: $2.438-11.215$ ]; $\mathrm{p}=0.000$ ), presence of hyperglycaemic imbalance (OR: 2.773 [IC 95\%: $1.121-6.856$ ]; $\mathrm{p}=0.024$ ) and an associated hypertension (OR: 2.782 (IC 95\%: 1.312 - 5.900]; $\mathrm{p}=0.007$ ).

\section{Discussion}

Our study gathered 142 patients aged on average over 55 years with a female predominance. This female predominance in this diabetic population has been already reported in our context [5].

More of our patients were type 2 diabetic. This diabetes has been known for more than 10 years on around half of them. The glycated haemoglobin average at $9 \%$ and the blood capillary glucose at $3.24 \mathrm{~g} / \mathrm{L}$ in our studied population witness the bad glycaemic balance of our patients. High Blood Pressure was the main associated cardiovascular risk factor in our series.

Several foot risk factors were present in our patients. It was about the use of unsuitable shoes particularly sandals and slippers. Also, more than $30 \%$ of our patients walked barefoot. However, this barefoot walking didn't significantly have an impact on the risk of foot lesion in our study contrary to what was report by the literature [6]. One should also point out the high prevalence of podiatric histories at risk such as prior foot ulceration and/or amputation found in $30 \%$ of the cases. Others foot risks such as neuropathy and arteritis were also checked in our patients. Therefore, the sensitivity on monofilament was missing in more than $60 \%$ of the cases.

The ABI was low in $34 \%$ of the cases and at least a patient out of four presented an abolition of the posterior tibial pulse which the specificity for the diabetic arteriopathy was highlighted [7]. Therefore, according to the IWGDF, over than $30 \%$ of our population of study were at a high foot risk. In a recent Tunisian study, a comparable amount was recorded (32.6\%) [8]. These data could be explained by the high prevalence of podiatric risk factors in our populations. The identification and the management of those factors are then unavoidable in

Table 2. Factors significantly associated with a diabetic foot in our series.

\begin{tabular}{ccc}
\hline Factors studied & $\mathrm{p}$ & OR (IC 95\%) \\
\hline Wearing closed shoes & 0.026 & $0.075[0.006-0.954]$ \\
Plantar keratosis & 0.024 & $2.878[1.119-7.399]$ \\
Absent monofilament sensation & 0.000 & $12.162[3.368-43.923]$ \\
Absence of pulse perception & 0.000 & $9.026[3.205-25.414]$ \\
\hline
\end{tabular}


the prevention of diabetic foot in our country.

The prevalence of the foot lesions in our study was estimated at $15.5 \%$. The average age of these patients was around 60 years and type 2 diabetics were predominant. This prevalence is close to the one recorded in prior African studies to ours [9]. In two-third of cases, these lesions were as ulceration. Plantar and toes localisation of these lesions correspond at what is classically reported in the literature [10]. Therefore, it's the areas of predilection that should attract a particular attention of the clinician while examining diabetic patients.

In our study, foot lesion risk factors were dominated by neuropathy, plantar keratosis and the absence of pulse perception. The presence of neuropathy is the main pathophysiological mechanism involved in the occurrence of ulceration on the diabetic patient [11]. The diagnosis of diabetic neuropathy by baresthesia defect after application of monofilament $10 \mathrm{~g}$ on the foot (Semmes-Weinstein 5.07) has an excellent sensibility and specificity to predict the foot ulceration risk [3] [12]. In our study population, neuropathy was more observed in 55-year-old individuals, with diabetes for more than 5 years, with associated hypertension and hyperglycaemic imbalance as demonstrated in the literature [13] [14]. In addition, wearing closed shoes was a protective factor for foot injury in our study population. Thus, targeted prevention measures are possible in our context, in particular by the management of plantar keratosis, the screening and monitoring of neuropathy and raising awareness of patients for the use of adapted footwear.

\section{Conclusion}

The importance of preventing the diabetic foot and the heavy morbidity and mortality that accompany it is well established. This prevention involves the identification and early management of risky feet. Our study shows that the podiatric risk of our diabetic inpatients is high. This risk is explained by the strong presence of foot risk factors such as inadequate footwear and especially the existence of neuropathy. Preventive measures are therefore recommended in the follow-up of diabetic patients, in particular by performing the monofilament test and raising awareness about the wearing of suitable shoes.

\section{References}

[1] Dehayem, M.Y., Choukem, S.P. and Sobngwi, E. (2016) Offloading of Diabetic Foot Ulcers in Limited Resource Settings. Medecine des Maladies Metaboliques, 10, 555-559.

[2] Mbaye, N.M., Sarr, A., Diop, S.N., et al. (2008) Descriptive Study of Diabetic Foot at the Marc Sankale Diabetes Center. Dakar Medical, 53, 205-212.

[3] Bakker, K., Apelqvist, J., Lipsky, B.A. and Van Netten, J.J. (2016) The 2015 IWGDF Guidance Documents on Prevention and Management of Foot Problems in Diabetes: Development of an Evidence-Based Global Consensus. Diabetes/Metabolism Research and Reviews, 32, 2-6. https://doi.org/10.1002/dmrr.2694

[4] Apelqvist, J., Bakker, K., van Houtum, W.H., Schaper, N.C., on behalf of the Inter- 
national Working Group on the Diabetic Foot (IWGDF) Editorial Board. (2008) Practical Guidelines on the Management and Prevention of the Diabetic Foot. Diabetes/Metabolism Research and Reviews, 24, S181-S187.

https://doi.org/10.1002/dmrr.848

[5] Diop, S.N., Wade, A., Lokrou, A., et al. (2013) Management of Type 2 Diabetes in Clinical Practices in Sub-Saharan Africa: Results of the AMAR-AFO Study in Senegal and Ivory Cost. Medecine des Maladies Metaboliques, 7, 363-367.

[6] Ogbera, O.A., Osa, E., Edo, A., et al. (2008) Common Clinical Features of Diabetic Foot Ulcers: Perspectives from a Developing Nation. The International Journal of Lower Extremity Wounds, 7, 93-98. https://doi.org/10.1177/1534734608318236

[7] Hartemann, A., Lecornet-Sokol, E. and Halbron, M. (2010) Arteriopathy of the Lower Limbs and Diabetes. In: Monnier, L., Ed., Diabétologie, Elsevier Masson, Paris, 263-271.

[8] Feleh, E.E., Bchir, N., Jaidane, A., et al. (2017) Podiological Risk Assessment in Diabetic Patients. Annales d Endocrinologie, 78, 431.

[9] Ndip, E.A., Tchakonte, B. and Mbanya, J.C. (2006) A Study of the Prevalence and Risk Factors of Foot Problems in a Population of Diabetic Patients in Cameroon. The International Journal of Lower Extremity Wounds, 5, 83-88. https://doi.org/10.1177/1534734606288413

[10] Richard, J.L., Lavigne, J.P., Got, I., et al. (2011) Management of Patients Hospitalized for Diabetic Foot Infection: Results of the French OPIDIA Study. Diabetes \& Metabolism, 37, 208-215. https://doi.org/10.1016/j.diabet.2010.10.003

[11] Martini, J. (2008) Diabetic Foot: Detection and Prevention. La Revue de Médecine Interne, 29, S260-S263. https://doi.org/10.1016/S0248-8663(08)73954-7

[12] Cheong, J., Alexiadou, K. and Devendra, S. (2017) Absent Monofilament Sensation in a Type 2 Diabetic Feet. London Journal of Primary Care (Abingdon), 9, 73-76. https://doi.org/10.1080/17571472.2017.1370813

[13] Hu, Y., Bakhotmah, B.A., Alzahrani, O.H., et al. (2014) Predictors of Diabetes Foot Complications among Patients with Diabetes in Saudi Arabia. Diabetes Research and Clinical Practice, 106, 286-294. https://doi.org/10.1016/j.diabres.2014.07.016

[14] Bruce, S.G. and Young, T.K. (2008) Prevalence and Risk Factors for Neuropathy in a Canadian First Nation Community. Diabetes Care, 31, 1837-1841.

https://doi.org/10.2337/dc08-0278 